\title{
LA ETAPA DE ADMISIBILIDAD DE LAS ACCIONES PARA LA DEFENSA DEL INTERÉS COLECTIVO Y DIFUSO DE LOS CONSUMIDORES
}

\author{
THE STAGE OF ADMISSIBILITY OF ACTIONS FOR THE DEFENSE OF THE \\ COLLECTIVE AND DIFFUSE INTERESTS OF CONSUMERS \\ LE STADE DE LA RECEVABILITÉ DES ACTIONS POUR LA DÉFENSE DES \\ INTÉRÊTS COLLECTIFS ET DIFFUS DES CONSOMMATEURS \\ Juan José Ossa Santa Cruz*, Luis Álvarez Estay ${ }^{* *}$
}

\section{INTRODUCCIÓN}

El procedimiento especial para la protección del interés colectivo y difuso de los consumidores (en adelante el "Procedimiento Colectivo"), fue incorporado a nuestra legislación en el año 2004, por medio de la Ley No $19.955^{1}$, que modificó la Ley No $19.496^{2}$ (en adelante la "LPC"). Dicho procedimiento permite la interposición de demandas colectivas, con la finalidad de contar con una herramienta procesal eficaz para dar solución efectiva a problemas que afecten (o puedan afectar) simultáneamente a un grupo de consumidores.

Para contrarrestar los efectos negativos que podría causar la proliferación de acciones colectivas frívolas, se incluyó una etapa previa de admisibilidad de la demanda. Desde su incorporación hasta la fecha, este examen de admisibilidad ha evidenciado un importante desarrollo legislativo y jurisprudencial. Dicha evolución, no exenta de problemas, amerita que hoy nos detengamos a analizar la forma en que esta etapa procesal ha sido entendida, tanto por los litigantes como por los tribunales de justicia.

\footnotetext{
*Abogado de la Pontificia Universidad Católica de Chile. Profesor Instructor Adjunto de Derecho Civil de esa casa de estudios. Master of Law, The London School of Economics. Director Nacional del Servicio Nacional del Consumidor.

${ }^{* *}$ Abogado. Licenciado en Ciencias Jurídicas y Sociales de la Universidad Alberto Hurtado. División Jurídica Servicio Nacional del Consumidor.

Quienes escriben este artículo hacen presente que el mismo da cuenta no sólo de su trabajo, sino del de diversos funcionarios del Servicio Nacional del Consumidor. Además, parte del contenido de este trabajo ya ha sido expresado en escritos judiciales públicos.

${ }^{1}$ Ley No 19.955, que modificó la Ley No 19.496, sobre Protección de los Derechos de los Consumidores, Diario Oficial, 14 de julio de 2004.

${ }^{2}$ Ley No 19.496, Establece Normas sobre Protección de los Derechos de los Consumidores, Diario Oficial, 7 de marzo de 1997.
} 
La etapa de admisibilidad en el procedimiento para la defensa del interés colectivo y difuso de los consumidores, fue establecida para evitar la litigación frívola. Sin embargo, esta etapa se desnaturalizó, transformándose en el principal obstáculo para que las acciones de clase fueran una herramienta efectiva de protección a los consumidores. Para poner remedio a esta situación, en el mes de octubre de 2011 se introdujeron modificaciones legales que simplificaron la etapa de admisibilidad. Sin embargo, algunos demandados todavía interpretan los actuales requisitos de admisibilidad erradamente, para dilatar la entrada al juicio propiamente tal. Pero dos recientes fallos debieran terminar con dichas interpretaciones.

En este trabajo revisaremos la evolución de la etapa de admisibilidad de las acciones de clase y daremos nuestra opinión acerca de cómo deben interpretarse los actuales requisitos de admisibilidad.

\section{Antiguo EXAMEN DE ADMISIBILIDAD}

Como adelantamos, el Procedimiento Colectivo fue incorporado el año 2004 a la LPC, y, con la intención de desincentivar la creación de una "industria del juicio colectivo", se agregó al procedimiento una etapa previa de admisibilidad, en la que el juez verificaría la presencia de cuatro requisitos. Sin embargo, dichos requerimientos se prestaron para que, en realidad, esta etapa de admisibilidad o antejuicio, que pretendía ser sólo un análisis formal, abriera la puerta para que se discutieran aspectos de fondo, existieran largos períodos probatorios y se interpusieran multiplicidad de recursos judiciales.

Así, pese a que los tribunales, al pronunciarse respecto de la admisibilidad de la demanda, en general lo hacían conforme al espíritu de esta etapa procesal ${ }^{3}$, ello no evitaba que, de forma previa al pronunciamiento, se generara un periodo de ardua y extensa litigación sobre aspectos que escapaban largamente del objeto del examen de admisibilidad.

Lo anterior, se sumaba al hecho que el juez podía recibir a prueba la admisibilidad de la demanda. Además, se estableció la procedencia del recurso de apelación en ambos efectos en contra de la resolución que se pronunciara acerca de la admisibilidad.

Los antiguos requisitos de admisibilidad, que estaban contemplados en el artículo 52 de la LPC, y que tantos problemas causaron, eran los siguientes:

\footnotetext{
${ }^{3}$ En relación a la forma en que, acertadamente, fallaron los tribunales respecto del antiguo examen de admisibilidad, véanse, por ejemplo, las siguientes sentencias: $18^{\circ}$ Juzgado Civil de Santiago, "Servicio Nacional del Consumidor con Cámara de Comercio de Santiago", 18 de enero de 2010, Rol No C-59862010, confirmada por la Ilustrísima Corte de Apelaciones de Santiago, 27 de octubre de 2011, Rol No 1922-2011; 23 Juzgado Civil de Santiago, "Servicio Nacional del Consumidor con Inmobiliaria Las Encinas de Peñalolén”, 26 de junio de 2009, Rol No C-14872-2008; e Ilustrísima Corte de Apelaciones de Santiago, "Servicio Nacional del Consumidor con Créditos Organización y Finanzas", 21 de junio de 2012, Rol No C-1663-2012.
} 
“a) Que la acción ha sido deducida por uno de los legitimados activos individualizados en el artículo 51.

b) Que la conducta que se persigue afecta el interés colectivo o difuso de los consumidores en los términos señalados en el artículo 50.

c) Que la acción deducida precisa las cuestiones de hecho que afectan el interés colectivo o difuso de los consumidores y los derechos afectados.

d) Que el número potencial de afectados justifica, en términos de costos y beneficios, la necesidad procesal o económica de someter su tramitación al procedimiento especial del presente Párrafo para que sus derechos sean efectivamente cautelados".

Específicamente, los problemas que hemos venido señalando (largas probanzas, análisis de elementos de fondo en esta etapa de admisibilidad, entre otros) se debieron a que, según se aprecia del antiguo artículo 52 de la LPC, (i) la conducta que se persiguiera debía "afectar" el interés colectivo o difuso; y (ii) el número potencial de afectados debía justificar, en términos de costos y beneficios, la necesidad procesal o económica de someter su tramitación al procedimiento especial de las acciones colectivas. En el primero de los casos, como puede apreciarse, existía una línea delgada entre lo que exigía el requisito de admisibilidad, con aquello que en definitiva era el objeto del juicio, esto es, la vulneración de los derechos de un colectivo de consumidores. En la segunda de las hipótesis, se abría la puerta para que cualquier argumento tuviera como (supuesto) fundamento que la acción, en términos de costos y beneficios, no se justificaba desde un punto de vista procesal o económico.

Sólo a modo ejemplar, a propósito de estos aspectos del antiguo control de admisibilidad, se discutieron asuntos como la prescripción y la existencia de daño a los consumidores en esta etapa de antejuicio. Si bien, como dijimos, en la mayoría de los casos los tribunales entendieron que este no era el espíritu de esta etapa procesal, lo cierto es que, de todas formas, hubo extensa litigación sobre estas materias.

\section{Actual examen de Admisibilidad}

De esta forma, luego de la interposición de las primeras acciones colectivas, se hizo evidente una desnaturalización de esta etapa de admisibilidad. Así, surgió una moción parlamentaria que buscó modificar el Procedimiento Colectivo, simplificando la etapa de admisibilidad para ajustarla a su espíritu original. Específicamente, se argumentó que:

"[las] actuales causales de admisibilidad (...) se han transformado, en los hechos, en una de las principales piedras de tope para una eficaz y correcta tramitación de estos juicios. Los retrasos en los juicios colectivos (...) se advierten principalmente en relación a esta etapa de admisibilidad (...), ya que en la práctica esta fase se ha convertido en una oportunidad de 
litigación y controversia prolongada sobre el fondo entre las partes, lo que ha llevado a etapas probatorias y la procedencia de recursos ordinarios y extraordinarios que en definitiva han retrasado en forma significativa la tramitación misma de la demanda colectiva"'.

Así, en octubre de 2011 se publicó la Ley No 20.5435, que eliminó los requisitos señalados más arriba, dejando subsistentes sólo dos (aunque con variaciones si se les compara con la redacción original). El actual artículo 52 de la LPC, señala lo siguiente:

"El tribunal examinará la demanda, la declarará admisible y le dará tramitación, una vez que verifique la concurrencia de los siguientes elementos:

a) Que la demanda ha sido deducida por uno de los legitimados activos individualizados en el artículo 51.

b) Que la demanda contiene una exposición clara de los hechos y fundamentos de derecho que justifican razonablemente la afectación del interés colectivo o difuso de los consumidores, en los términos del artículo 50 ".

Además, se suprimió la posibilidad que el juez recibiera la admisibilidad a prueba, así como también se estableció que la apelación en contra de la resolución que declara admisible la demanda colectiva, tiene solo efecto devolutivo.

Sin embargo, aun cuando la mejora fue sustancial, los problemas no terminaron. Concretamente, y ahora a propósito de los dos requisitos de admisibilidad que subsistieron a la modificación legal, algunos demandados han pretendido discutir asuntos de fondo o, al menos, derechamente impertinentes, en la etapa de admisibilidad. A continuación ofreceremos algunos ejemplos de lo anterior, analizaremos dos recientes fallos que debieran poner fin a dichos intentos y, luego, daremos nuestra opinión en relación a cómo deben entenderse los actuales requisitos de admisibilidad.

\subsection{Artículo 52, letra a), de la LPC}

Como señalamos anteriormente, el primer requisito de admisibilidad exigido (letra a) del artículo 52 de la LPC) es que la demanda haya sido deducida por algún legitimado activo de los señalados en el artículo 51 de la misma ley, esto es: El Servicio Nacional del Consumidor (en adelante el "Sernac"), una Asociación

\footnotetext{
${ }^{4}$ Historia de la Ley No 20.543. Relativo al Procedimiento Aplicable para la Protección del Interés Colectivo o Difuso de los Consumidores. Biblioteca del Congreso Nacional de Chile (BCN). Valparaíso, 2011, p. 5. Disponible en: <http://www.leychile.cl/Navegar/scripts/obtienearchivo?id=recursoslegales/10221.3/36531 /1/HL20543.pdf>[consulta: 26 octubre 2013].

${ }^{5}$ Ley No 20.543, Relativo al Procedimiento Aplicable para la Protección del Interés Colectivo o Difuso de los Consumidores, Diario Oficial, 21 de octubre de 2011.
} 
de Consumidores (que cumpla los requisitos ahí indicados) o un grupo de consumidores afectados en un mismo interés, no inferior a 50 personas ${ }^{6}$.

Partamos por señalar qué significa que alguien tenga legitimación activa. Como se ha reconocido y en lo que importa a este trabajo, la legitimación activa es la potestad legal para acudir a un órgano jurisdiccional para iniciar un juicio, aptitud que se tiene porque se es titular del derecho que se invoca, o bien porque se cuenta con la representación legal de dicho titular 7 .

En este sentido, el Sernac es el legitimado activo por excelencia para interponer una demanda colectiva. En efecto, es la propia LPC la que le da poderes públicos para asumir la representación del colectivo de consumidores afectados, sin siquiera necesitar acreditar la representación de consumidores determinados del colectivo en cuyo interés actúal (como lo dicen expresamente los artículos 51 No 1 y 4 de la LPC).

¿Cuándo entonces el Sernac no tendría legitimación activa para deducir una demanda colectiva? La respuesta nos parece una sola: cuando no aparece de la demanda que esté representando a un colectivo sino a un consumidor en forma individual, cuestión esta última que le está vedada por ley, según ha resuelto la Contraloría General de la República ${ }^{8}$. Más específicamente, quienes tienen legitimación activa para iniciar un procedimiento para la protección del interés individual son los propios consumidores afectados (lo hacen ante el Juez de Policía Local). Por su parte, el Sernac puede deducir acciones judiciales cuando se afecta el interés general (ante el Juez de Policía Local) o en el interés colectivo o difuso de los consumidores (en cuyo caso recurre al Juez Civil).

Sin embargo, en los diversos juicios colectivos tramitados por el Sernac, incluso una vez que fue reformado el control de admisibilidad, las demandadas han atacado el cumplimiento de este requisito desde diversas ópticas, todas a nuestro juicio desajustadas a derecho.

Por ejemplo, en un juicio colectivo seguido en contra de una institución bancaria, el demandado argumentó que el Sernac no tendría legitimación activa pues, a su juicio, habría sido demandado ante los Juzgados de Policía Local por las mismas razones, en forma anterior. Como se aprecia, lo que se pretendió fue disfrazar la excepción de litispendencia en una de falta de legitimación activa. Por cierto, tampoco concurrían los requisitos para que procediera la primera, pues la causa, el objeto y lo pedido diferían en forma clara (al punto que se trataba de

\footnotetext{
${ }^{6}$ Además, existen algunas hipótesis especiales de legitimación activa en materia de acciones colectivas, escasamente utilizadas al día de hoy. Por una parte, actualmente la Ley General de Urbanismo y Construcción, Decreto No 458 del Ministerio de Vivienda y Urbanismo, en su artículo 19 faculta a un grupo no inferior a 6 propietarios para someterse al Procedimiento Colectivo. Además, la Ley No 20.416, que Fija Normas Especiales para las Empresas de Menor Tamaño, faculta a éstas para el inicio de acciones colectivas.

${ }^{7}$ Calamandrei, Piero (1973). Instituciones del Derecho Procesal Civil según el nuevo Código. Buenos Aires: Ed. EJEA. T. I, p. 262.

${ }^{8}$ Dictamen Contraloría General de la República No 71.087, 4 de noviembre de 2013.
} 
distintas sedes judiciales). Este argumento del banco demandado fue desechado, tanto en primera como en segunda instancia9.

En otros casos, se ha pretendido confundir la excepción de falta de legitimación activa con la falta de legitimación pasiva. Por ejemplo, alguna empresa ha argumentado que no sería proveedor a la luz de la LPC y, en consecuencia, no podría ser sujeto de una demanda colectiva. Como se ve, en realidad se estaba oponiendo una excepción de falta de legitimación pasiva, en circunstancias que, al menos para el derecho del consumidor, ésta no tiene su correlativo en la legitimación activa del Sernac. Esta argumentación también fue desechada por los tribunales ${ }^{10}$.

En el contexto del juicio colectivo que inició el Sernac en contra de las tres cadenas más grandes de farmacias del país, se argumentó una supuesta falta de legitimación activa fundada en el hecho de que el Sernac no compareció ante el Honorable Tribunal de Defensa de la Libre Competencia en el procedimiento que derivó en la sentencia dictada por dicho tribunal. Además, se sostuvo que el Sernac no podría invocar el artículo 30 del Decreto Ley 211, que permite reclamar los perjuicios causados fruto de un ilícito anticompetitivo, pues dicho artículo menciona el juicio sumario y no el Procedimiento Colectivo.

Ambos argumentos fueron desechados recientemente por la Ilustrísima Corte de Apelaciones de Santiago, en un fallo que, esperamos, ilumine en forma definitiva los fallos que están por venir en esta materia. Concretamente, dicho tribunal de alzada resolvió lo siguiente:

"El que no se haya hecho parte en la causa seguida ante el Tribunal de la Libre Competencia, carece de toda significación, como también el que se someta la acción deducida al procedimiento reglamentado en los artículos 51 y siguientes de la misma ley y no al juicio sumario de aplicación general, puesto que de este hecho no puede derivar perjuicios para los demandados, ya que no importa restricción alguna al ejercicio de sus derechos en el juicio" 11 (Considerando 3º, Párrafo 3).

\section{Artículo 52, LeTra B), DE LA LPC}

Como puede apreciarse, con este requisito de admisibilidad el legislador estableció una figura similar a la de la ineptitud del libelo. Tomando en cuenta que este requisito tiene como principal función prevenir que existan demandas colectivas

\footnotetext{
${ }_{9}$ Vid. 30 Juzgado Civil de Santiago, "Servicio Nacional del Consumidor con Banco Bilbao Vizcaya Argentaria Chile”, 12 de octubre de 2012, Rol No C-19.203-2012.

Ilustrísima Corte de Apelaciones de Santiago, "Servicio Nacional del Consumidor con Banco Bilbao Vizcaya Argentaria Chile", 6 de marzo de 2013, Rol No C-8753-2012.

10 Vid. 160 Juzgado Civil de Santiago, "Servicio Nacional del Consumidor con Servicio y Administración de Créditos Comerciales Presto S.A.”, 30 de abril de 2012, Rol No C-17.556-2011.

${ }^{11}$ Ilustrísima Corte de Apelaciones de Santiago, "Servicio Nacional del Consumidor con Farmacias Ahumada S.A. - Farmacias Cruz Verde S.A. - Salcobrand S.A.”, 2 de diciembre de 2013, Rol No 3908-2013.
} 
que no son serias, se exige no sólo que se precisen los hechos y fundamentos de derecho, sino que los mismos justifiquen razonablemente que se haya afectado el interés que se invoca.

Pues bien, ha sido a propósito de esto último (“justificar razonablemente que se ha afectado el interés que se invoca”) que han surgido diversas interpretaciones.

Por ejemplo, en un juicio colectivo seguido por el Sernac en contra de dos empresas relacionadas, una de ellas alegó que la demanda sería inadmisible, pues no se cumpliría con haber justificado razonablemente que se había afectado el interés que se invocó. Ello, pues, según la demandada, en ese caso no había daño a los consumidores ni infracción a la LPC. Como se ve, una excepción de fondo, tal vez la más de fondo de todas (ausencia de daño y de infracción) fue alegada en la etapa de admisibilidad, cuando las partes ni siquiera habían rendido prueba. La alegación en cuestión fue, primero, rechazada en primera instancia y, luego, acogida por el tribunal de alzada. Pero, en definitiva, el argumento dado por la empresa fue rechazado por la Excelentísima Corte Suprema, la que, de paso, fijó con claridad qué significa que la demanda colectiva deba contener fundamentos de hecho y de derecho que justifiquen razonablemente que se ha afectado el interés que se invoca ${ }^{12}$.

Específicamente, el Máximo Tribunal determinó que:

“(...) la revisión del requisito de admisibilidad contemplado en la letra b) del artículo 52, permite advertir que son elementos del mismo: que la demanda describa o explique los motivos principales o de fondo, tanto en los hechos como en el derecho aplicable y, además, que esos fundamentos sean capaces de poner manifiesto, de modo razonable, que el perjuicio a los consumidores ha tenido o está teniendo lugar"13 (Considerando 16º, Párrafo 1).

Además, la Excelentísima Corte Suprema agregó que:

“(...) al abocarse a la exigencia legal de admisibilidad en comento, el tribunal habrá de verificar, primero, si el texto de la demanda exhibe motivos fundados en lo fáctico y en lo jurídico; en seguida, si éstos son inteligibles, vale decir, si permiten un objetivo entendimiento $y$, por último, si esos fundamentos conllevan, medianamente - no en plenitud, pero en algún grado - el desmedro del interés colectivo o difuso de los consumidores" 14 (Considerando 170, Párrafo 1).

12 160 Juzgado Civil de Santiago, "Servicio Nacional del Consumidor con Servicio y Administración de Créditos Comerciales Presto S.A.”, 14 de diciembre de 2011, Rol No C-17.556-2011.

Ilustrísima Corte de Apelaciones de Santiago, "Servicio Nacional del Consumidor con Servicio y Administración de Créditos Comerciales Presto S.A.”, 28 de septiembre de 2012, Rol No 3279-2012.

Corte Suprema, "Servicio Nacional del Consumidor con Servicio y Administración de Créditos Comerciales Presto S.A.”, 20 de agosto de 2013, Rol No 9010-2012.

${ }^{13}$ Corte Suprema, "Servicio Nacional del Consumidor con Servicio y Administración de Créditos Comerciales Presto S.A.”, 20 de agosto de 2013, Rol No 9010-2012.

${ }_{14}$ Ídem. 
Adicionalmente, el Máximo Tribunal argumentó que:

“(...) las ideas que se vienen anotando llevan incardinada una distinción que amerita ser puesta de relieve y, es que no debe confundirse la admisibilidad de una acción (...) con la procedencia de la demanda que la endereza. En efecto, esa admisibilidad es tributaria de la confluencia cabal de los aspectos que el legislador ha escogido para considerar que el demandante actúa premunido de un interés jurídicamente significativo y que su acción tiene fundamentos serios o de consideración indicativos del menoscabo del interés de una pluralidad de consumidores. La procedencia de la demanda, en cambio, es cosa diferente, pues se refiere a la conformidad que ha de existir entre las razones de fondo de la pretensión procesal con los dictados del ordenamiento jurídico en la materia que ella envuelve, determinando, en consecuencia, el resultado final plasmado en la sentencia"15 (Considerando $15^{\circ}$, Párrafo 1).

Es decir, se estableció claramente que, lo que en este requisito se exige, es que en la demanda se expresen, de forma clara, los fundamentos que evidencien la posibilidad de existir una vulneración al interés colectivo y/o difuso de los consumidores. En otras palabras, no se exige que se acredite que se vulneró dicho interés.

Lo anterior resulta de toda lógica, por cuanto una interpretación en contrario llevaría al absurdo de tener que interponerse la demanda colectiva acompañada de todos los medios probatorios, ya que sería la única forma de demostrar al tribunal, antes de que se pronuncie sobre su admisibilidad, que se afectó el interés colectivo. Como ello implicaría una carga sumamente injusta para el demandante, el legislador sólo estableció que, en la demanda, deben señalarse los fundamentos de los cuales se desprenda medianamente la afectación (o potencial afectación) de un interés colectivo y/o difuso.

\section{CONCLUSIONES}

La etapa de admisibilidad de la demanda colectiva fue establecida para prevenir la litigación frívola y evitar una industria del litigio. Sin embargo, esta etapa procesal se desnaturalizó, transformándose en un obstáculo para la ágil tramitación de este tipo de juicios. En este sentido, las modificaciones legales realizadas en el mes de octubre de 2011, han logrado inyectarle rapidez al procedimiento. Lo anterior, sumado a los recientes fallos, analizados anteriormente, generan un panorama auspicioso en cuanto a la posibilidad de entregar una protección efectiva a los consumidores a través del Procedimiento Colectivo.

En definitiva, el Sernac, siempre que represente a un colectivo de consumidores, cuenta con legitimación activa para iniciar un Procedimiento Colectivo. Además, deberá señalar en su demanda los hechos y fundamentos de derecho que permitan, razonablemente, hace pensar al juez que se ha afectado (o que se afectará) a ese

15 Ídem.

Revista de Derecho - Escuela de Postgrado No 4, diciembre 2013 
colectivo que representa. Con ello, basta para dar cumplimiento a los requisitos de admisibilidad de la demanda colectiva señalados en el artículo 52 de la LPC.

Finalmente, cabe señalar que, el análisis que se contiene en este trabajo, no significa que no puedan hacerse otras mejoras al Procedimiento Colectivo. De hecho, existen diversos aspectos que pueden ser modificados, los que esperamos tratar en otra oportunidad. 